\title{
Foreword
}

\section{Special Issue: Symposium on the Chemistry of Terpenes, Essential Oils and Aromatics (TEAC)}

It is a great honor that we are bestowed the opportunity by the Journal of Oleo Science (JOS) to prepare the second special issue vol. 67, (10) 2018, comprising the twelve contributed papers in English to celebrate the $60^{\text {th }}$ Anniversary Meeting of Symposium on the Chemistry of Terpenes, Essential Oils and Aromatics (TEAC).

As you are aware, 61 years ago TEAC started at Kindai University (Former name: Kinki University) by holding the inaugural general assembly hosted by Professor Nenokichi HIRAO. We were fortunate to continue this annual symposium event for 61 years, in the process holding meetings in every prefecture of Japan, without exception. This resulted in the 58th TEAC conference at Wakayama University (Wakayama) in 2014, and the completion of the first cycle of meeting visits. The following year, 2015, to celebrate the start of the second round and of meeting sites, and to commemorate our 60th anniversary, Professor Mitsuo MIYAZAWA organized the 59th TEAC special meeting at our birthplace, Kindai University in Osaka. About 600 participants from all over the world, including the United States, France, Poland, Turkey, Indonesia, Malaysia, and Thailand gathered for the meeting. Our symposium is known as the only academic and scientific research meeting for these specialized fields of research in the world. It was held grandly every year, the 60th, 61st and 62nd TEAC conference at Tokyo University of Agriculture (Abashiri, Hokkaido) in 2016 by Prof. Takane FUJIMORI, Kanazawa Institute of Technology (Kanazawa) in 2017 by Prof. Shinobu ODA, and Nagasaki University (Nagasaki) in 2018 by Prof. Takashi TANAKA, respectively.

Finally, we sincerely appreciate our colleagues who contributed papers to the society meeting and to this issue of JOS 2018.

Best wishes to all our scientific colleagues around the world, and we hope to see you at a future meeting of TEAC.

Mitsuo MIYAZAWA, Ph. D.

Director of the TEAC

Executive Editor of Journal of Oleo Science

Professor, Nara Institute of Science and Technology (NAIST)

Professor Emeritus, Kindai University
Yoshinori ASAKAWA, Ph. D.

President of the TEAC

Professor, Tokushima Bunri University 